\title{
Super-Helix Formation induced by Cyanine J-Aggregation onto Random-Coil Carboxymethyl Amylose as Template
}

Oh-Kil Kim ${ }^{1 *}$, Jongtae Je ${ }^{1}$, Glenn Jernigan ${ }^{2}$, Leonard Buckley ${ }^{1}$, David Whitten ${ }^{3}$

${ }^{1}$ Chemistry Division, ${ }^{2}$ Electronic Science Division and Institute for NanoScience

Naval Research Laboratory, Washington, DC 20375-5342

${ }^{3}$ Department of Chemical \& Nuclear Engineering, University of New Mexico, Albuquerque, NM 87131

\section{Supporting Information:}
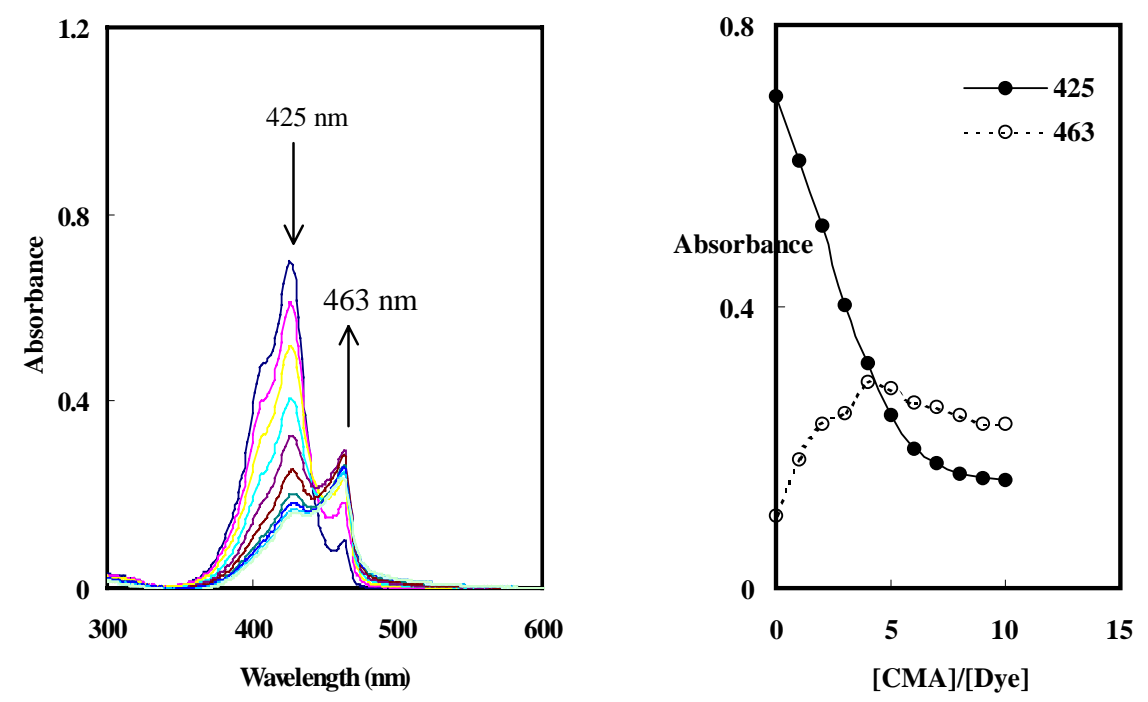

Figure S-1a. Concentration effect of CMA (DS=1.53) on J-aggregation of cyanine-1 dye in water: J-band $\left(\lambda_{\max }=463 \mathrm{~nm}\right)$, monomer band $\left(\lambda_{\max }=425 \mathrm{~nm}\right) .[$ Cyanune- 1$]=1 \times 10^{-5} \mathrm{M},[\mathrm{CMA}(\mathrm{DS}=1.53)]=0$ $\sim 1 \times 10^{-4} \mathrm{M}$.
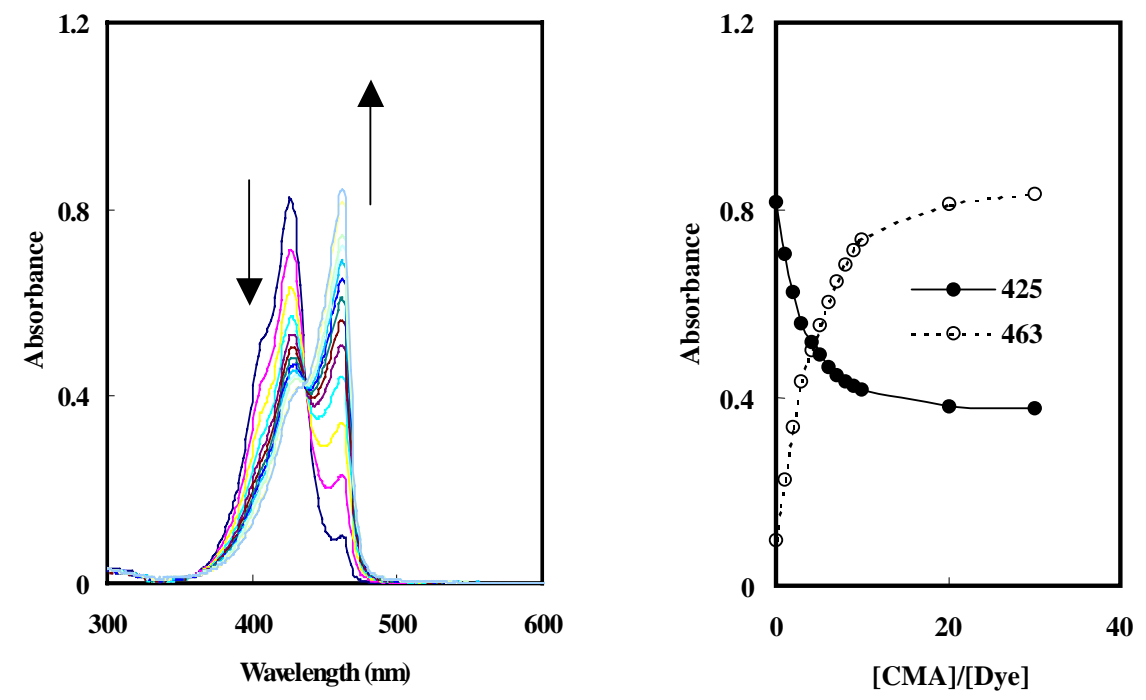

Figure S-1b. Concentration effect of CMA (DS=1.53) on J-aggregation of Cyanine-1 dye in $10 \% \mathrm{MeOH}$ mixture. $\left[\right.$ Cyanune-1] $=1 \times 10^{-5} \mathrm{M},[\mathrm{CMA}(\mathrm{DS}=1.53)]=0 \sim 3 \times 10^{-4} \mathrm{M}$ 

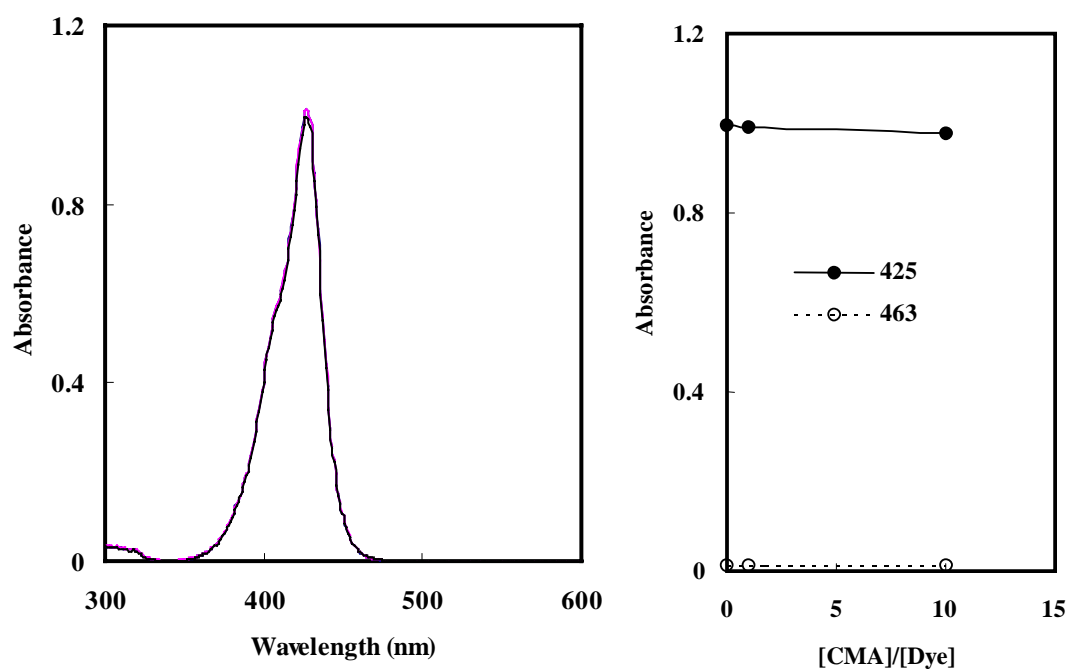

Figure S-1c. Concentration effect of CMA (DS=1.53) on J-aggregation of cyanine-1 in 50\% $\mathrm{MeOH}$ mixture. $[$ Cyanine- 1$]=1 \times 10^{-5} \mathrm{M},[\mathrm{CMA}(\mathrm{DS}=1.53)]=0 \sim 1 \times 10^{-4} \mathrm{M}$
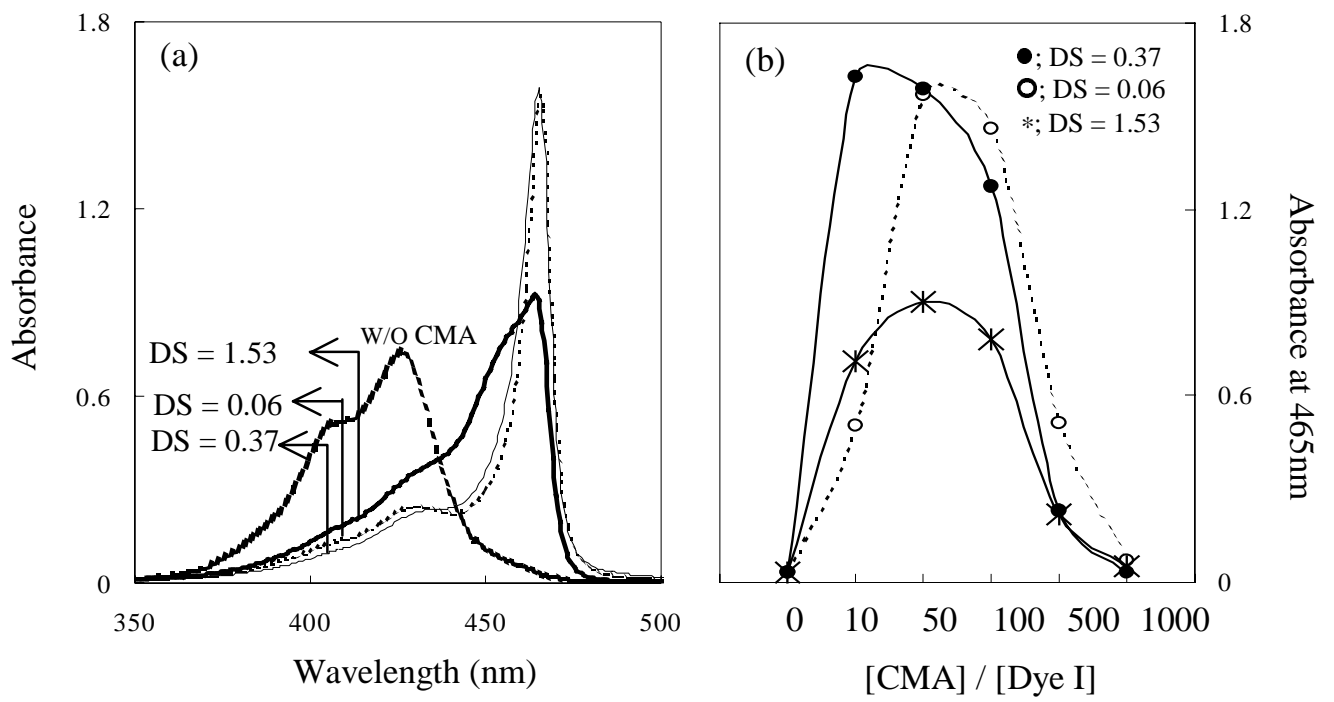

Figure S-2. DS effect of CMA on UV-Vis spectra (a) and on the absorption (b) of the J-band maximum (at $465 \mathrm{~nm}$ ) of Cyanine dye in water $(\mathrm{pH}=6-7)$ : for (a), [Dye] $=1 \times 10^{-5} \mathrm{M}$ and $\mathrm{CMA}]=5 \times 10^{-4} \mathrm{M}$; for $(\mathrm{b}) ;[$ Cyanine- 1$]=\left[1 \times 10^{-5} \mathrm{M}\right]$ and $[\mathrm{CMA}]=0 \sim 5 \times 10^{-1} \mathrm{M}$. 


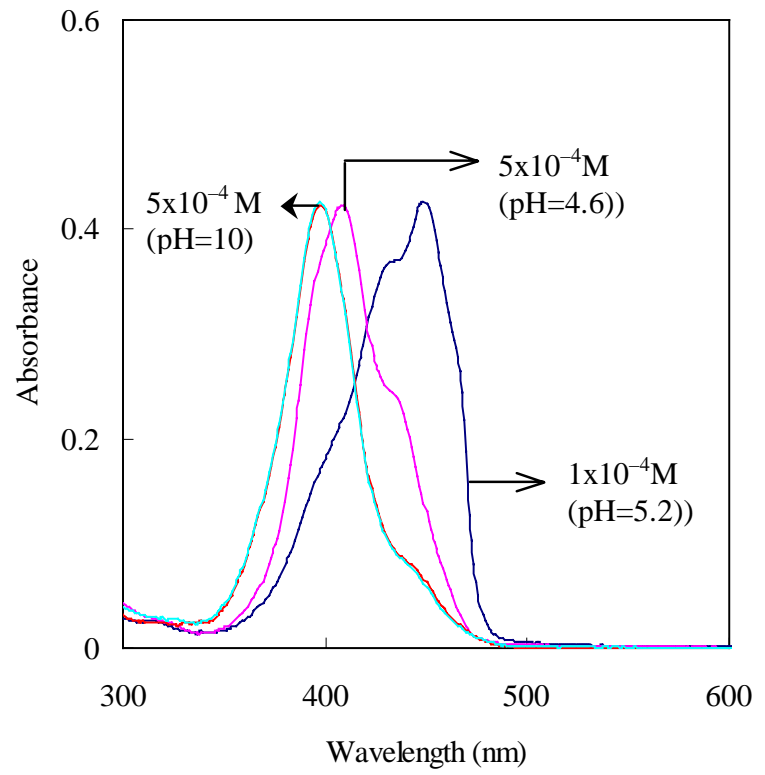

Figure S-3a. Effects of PAA concetration and $\mathrm{pH}$ on absorption spectra of Cyanine-1 J-aggregation in water; $[$ Cyanine- 1$]=1 \times 10^{-5} \mathrm{M},[\mathrm{PAA}]=1 \times 10^{-4}$ and $5 \times 10^{-4} \mathrm{M}$.

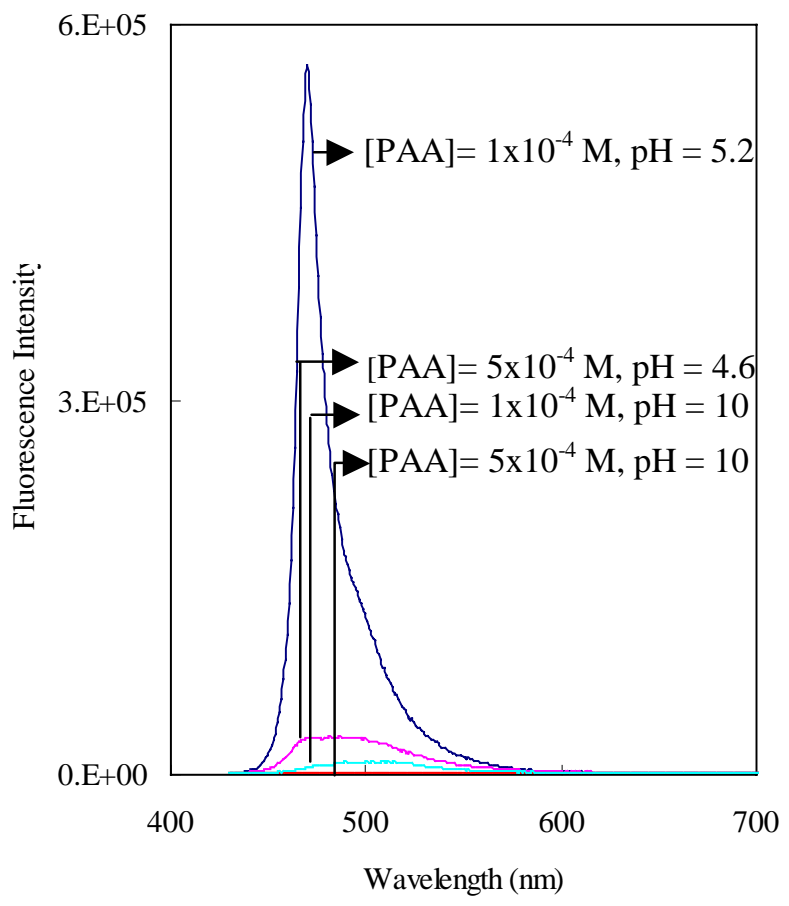

Figure S-3b. Effects of PAA concentration and $\mathrm{pH}$ on the fluorescence intensity of Cyanine J-aggregation in water: $[$ Cyanine- 1$]=1 \times 10^{-5} \mathrm{M},[\mathrm{PAA}]=1 \times 10^{-4}$ and $5 \times 10^{-4} \mathrm{M}$. 


\section{Experimental Section}

Materials. Cyanine-1 was obtained from the Center for Photoinduced Charge Transfer, University of Rochester. Amylose $(\mathrm{Mw} \approx 80 \mathrm{kDa}$ ) and Poly(acrylic acid), PAA, are commercial products (Aldrich Chemicals) and used as received. CMA was prepared by modifying the literature procedure ${ }^{1}$ by reacting amylose with chloroacetic acid in aq sodium hydroxide at $45-50{ }^{\circ} \mathrm{C}$ at a different reaction time that gives various degrees of substitution (DS) per glucose unit. The high DS (=1.53) CMA is a commercial product (Aldrich). The resulting Na salt of CMA was acidified and dialyzed for salt-free acid form. The $\mathrm{pH}$ was adjusted by adding dil $\mathrm{NaOH}$ when needed. The DS of CMA was determined by titration.

Absorption and fluorescence spectroscopy. Supramolecular cyanine dye J-aggregation was processed by gradual addition of aq CMA solution to cyanine-1 solution in water (or methanol mixture) with stirring. Absorption and emission spectra were recorded using Cary UV-Vis-NIR spectrometer (Varian) and DN3000 Fluorescence Spectrometer (SPEX Industries, Inc.), respectively. Sample solutions for absorption spectra were made by dilution of the stock solution $\left(1 \times 10^{-3} \mathrm{M}\right.$ dye dissolved in deionized water) with water or methanol to a desired dye concentration $\left(1-2 \times 10^{-5} \mathrm{M}\right)$ and methanol content. The J-aggregation studies were made based on the absorption and emission spectra at various CMA concentrations $\left(1-3 \times 10^{-4} \mathrm{M}\right)$ to the fixed cyanine dye concentration.

Circular Dichroism (CD) spectra of cyanine J-aggregates in the presence of CMA. CD spectra of the sample solutions were recorded with Jasco J-500C spectropolarimeter using 1-cm cylindrical quartz cell with a constant temperature $\left(25^{\circ} \mathrm{C}\right)$. The cyanine dye/CMA complexes are very stable and no measurable changes were observed in the spectra over several months at room temp.

Atomic Force Microscopy (AFM) Measurements. A Si chip (13 mmx13 mm) was treated with conc $\mathrm{NH}_{4} \mathrm{OH}$ and $30 \% \mathrm{H}_{2} \mathrm{O}_{2}$ to produce a hydrophilic surface by using the established technique; $\mathrm{SiO}_{2} / \mathrm{Si}$ as substrate. A dilute aq solution of cyanine-1/CMA $(\mathrm{DS}=1.53)$ mixture $\left(\left[1 \times 10^{-5} \mathrm{M}\right] /\left[5 \times 10^{-4} \mathrm{M}\right]\right)$ was dropcast as a thin layer onto the substrate and air-dried at room temp. AFM is done using Digital Instruments Nanoscope III in tapping mode. Reverse aspect AFM tips are used for increased sensitivity. Images are taken at multiple locations on each square in ranges of 10,5 and $2 \mu \mathrm{m}$ for $\mathrm{X}$ and $\mathrm{Y}$ directions. A background subtraction is done on all images to account for any tilt of the sample while in the AFM.

(1) Hui, Y.; Winkle, J.R.; Whitten, D.G. J. Phys. Chem. 1983, 87, 23-25. References therein. 